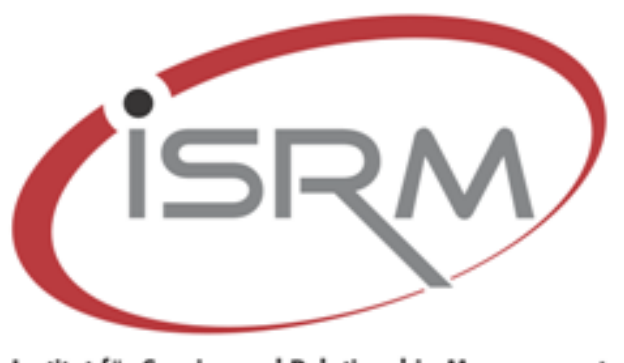

Institut für Service und Relationship Management
Universität Leipzig

Wirtschaftswissenschaftliche Fakultät

Institut für Service und Relationship

Management

Lehrstuhl für BWL, insbs. Marketing

Referenz Verlagsversion/Published in

final edited form as:

Service Science, 2014 September; Vol. 6,

No. 3, pp. $190-205$

DOI:

http://dx.doi.org/10.1287/serv.2014.007

7

\title{
SignS AND PRACTICES AS RESOURCES IN IT-RELATED SERVICE INNOVATION
}

\author{
Helge Löbler, Robert F. Lusch \\ Leipzig University, University of Arizona
}

\begin{abstract}
Emerging from the rapid growth of information technology (IT) in a digital world is the explosion and rapid ascent of IT-related service innovation occurring around the globe. All successful service innovation in a digital world consists of two main abstract domains: signs (because only signs can be digitized) and practices. Signs are perceivable, but practices are not. Signs are commonly understood as resources in the digital world, whereas practices are understood as providing context, not as resources. This article proposes a change in this perspective: according to service-dominant logic, both signs and practices can become resources for service and value cocreation. They become resources if they are integrated in a service offering. We illustrate how recent digital service innovations can be explained with this perspective and how it can be used to distinguish incremental from radical innovation. The article also suggests, using this perspective, that IT and innovation specialists can productively develop ideas and concepts for future service innovation. From the practices framework presented, directions for further research are discussed.
\end{abstract}

\section{Keywords}

signs; practices; IT-related service; service innovation; resources 


\section{Introduction}

The service revolution and service innovation are inextricably linked to the information technology (IT) revolution (Rai and Sambamurthy 2006, Sheehan 2006). Rust (2004) argues that the service and the IT revolutions are the flip sides of the same coin because service is primarily driven by knowledge and information. Furthermore, Lusch et al. (2007) discuss how four megatrends - namely, movements to open standards, increased connectivity of people and objects, network ubiquity, and higher degrees of human specialization-all point in the direction of more service exchange, sparking service innovations and hence service markets. Consequently, much service innovation will be IT-related.

To broadly understand IT-related service innovation, we develop a pretheoretic framework that is built around the concepts of signs and sign systems on the one hand and the theory of practices on the other. We define signs "as something that is perceivable, something we become aware of through our senses" (Löbler 2010, p. 220) or, in an IT world, something that can be digitized. A set of interrelated signs can be thought of as a sign system. ${ }^{1}$ For practices, we use Reckwitz's (2002) definition: "A practice is thus a routinized way in which bodies are moved, objects are handled, subjects are treated, things are described and the world is understood" (p. 250). We also emphasize that "this way of understanding is largely implicit" (Reckwitz 2002, p. 249).

We argue that both signs and practices can become resources in IT-related services. Furthermore, we elaborate on how successful innovations are institutionalized into practices integrated in IT-related service offerings. Our intent is to show that service innovation in a digital world can be understood as inherently dealing with signs and their reconnection with the real world. There is no innovation without the real world of things and humans and their practices. We discuss how they are connected and how these connections provide insights into perspectives of innovation. We show how signs and practices in particular become resources when integrated in a service-providing process.

In the framework developed, signs and practices are the units of analysis. Both are modes of operation. Our ontology is based neither on individual humans nor on human states; it is instead based on the ontology of practices and operating with signs. It is an enquiry in line with modern social system theory (Luhmann 1995, 2006), practice theory (Schatzki 1996), and social constructionism (not to be confused with social constructivism) (Gergen 1991, 1994, 1999), in which modes of operation are social rather than individual.

The rest of this article is organized as follows: We begin by distinguishing signs from practices but by also recognizing they are two sides of one coin. Despite being two sides of the same coin, signs and signs systems and practices and practice theory have been studied by different disciplines. In the literature review, we show that signs and practices neither are explicitly connected nor are seen as resources. Based on this review, we then describe our understanding of signs and practices. We pay particular attention to the rapid and explosive growth of signs and sign systems since the advent of the digital computer and the Internet, and we discuss how this has created a global cultural system based on signs and sign systems and disembedded systems (Nambisan and Sawhney 2007, Kallinikos et al. 2013). Next, we draw on a framework developed by Löbler (2010) on how signs are connected to coordinate behavior, meaning, and thoughts, and we significantly expand this to show how signs connect with practices and how signs and practices become resources in IT-related service innovation. With this framework, we show how past IT-related service innovations can be better understood, why

\footnotetext{
${ }^{1}$ Whereas others have used the term "symbol" and symbol system, we use the term "sign." There is long-standing debate on the difference between signs and symbols; in our terminology, a symbol (from the Greek $\sigma$ v́ $\mu \beta o \lambda o \nu$ (sýmbolon) and $\sigma v \mu \beta \alpha \lambda \omega$ (symbállo, meaning "to put together")) is the combination of a sign and a practice that gives the sign symbolic meaning, as we will explain later.
} 
some digital service innovations survive and prosper, and the important role of organizations embracing a service orientation. Finally, we develop research directions based on the framework and offer concluding observations.

\section{Service Innovation}

\section{Realms of Signs}

We begin by giving a more detailed explanation of the consequences of the modern IT or digital world. Almost everyone in the world has access to nearly all kinds of signs in nearly every place and at every time, and thus a limiting factor for using signs is no longer technical but the human capacity to understand, process, and beneficially use all the signs available. Consequently, service innovations in a digital world must face the limited capacity of human beings to handle and process all the signs now available. In a digital age, as in past social and economic ages, service innovations that enhance human activities or support new human activities are almost always connected with the material or tangible world. They are also connected with real people, who want to use the service the innovation affords.

What seems to be relatively different today when contrasted with the predigital age is access to and distribution of signifiers and signs - which form the basis of innovation - that were relatively scarce in the past. Even with the emergence and development of signs through most of human civilization, they may not have been widely available or distributed. Often this was due not only to technological reasons but also to political and religious reasons, as well as the constraints on physically moving signs when they were embedded only in tangible matter (e.g., stone tablets, paper books).

Symbolic Token as a Realm of Signs. Moving from a material-based human and societal system, the evolutionary direction moves toward a sign-based information-, symbolic-, and immaterial-based abstract system (Giddens 1991, Hasenfeld 1992, Lyotard 1984, Normann 2001). Following Giddens (1991), societal systems can be divided into face-to-face systems and faceless commitments: "The former refers to trust relations which are sustained by or expressed in social connections established in circumstances of copresence. The second concerns the development of faith in symbolic tokens or expert systems, which, taken together, I shall term abstract systems" (p. 80, italics in original). In addition, Giddens contrasts these with expert systems, "systems of technical accomplishment or professional expertise that organize large areas of the material and social environment in which we live today" (p. 27). Modern life is full of expert systems. Expert systems emerge according to the division of labor and specialized skills or knowledge. Thus, they are part of the modern service society.

More important for realms of signs is the symbolic token: "By symbolic tokens, I mean media of interchange which can be 'passed around' without regard to the specific characteristics of individuals or groups that handle them at any particular juncture" (Giddens 1991, p. 22). According to Giddens, a symbolic token disembedded from reality does not need a reality to be understood. Symbolic tokens are comparable to the character of mediated currencies. They refer to something but do not need the referred object to be exchanged. Money is an example of a symbolic token; it is commonly understood what $\$ 5$ or $€ 5$ mean. In addition, it is commonly understood what it means when a child comes home from school with an A, and most people understand that AAA is a good bond securities rating. Hence symbolic tokens create a realm of signs. 
Simulacrum as a Realm of Signs. According to Baudrillard (1975, p. 128), "The sign no longer designates anything at all. It approaches its true structural limit which is to refer back only to other signs." Following Baudrillard $(1975,1998)$ and Derrida $(1976,1977,1978)$, when referring to signs, we must abstract from the signified, because signs only refer back to signs, and we define words or terms using other words and terms. We do not have access to abstract signifieds (e.g., "service") outside of language. We can only describe service by using other words. For example, even if we think about customers and their behavior as a signified for the word "service," as soon as we begin to describe the customers or their behavior, we are "lost in language use," according to the poststructuralist (postmodern) perspective. It becomes a simulacrum, in which the "simulacrum is never what hides the truth - it is truth that hides the fact that there is none. The simulacrum is true" (Baudrillard 1994, p. 1). In this sense, the evolving IT world supports the emergence of Giddens' (1991) disembedded abstract systems and signs, and with them, information becomes independent of the "real" world and simultaneously is taken to "be real." Seals of quality are an example: People often treat seals as if they were quality, but they are not; they are signs that indicate quality. People cannot always assess quality, so they substitute the mark (trademark or service mark) or the brand for quality. Even if the quality (accidentally or for other reasons) is bad, they believe it is good because of the mark or brand.

Market as a Realm of Signs. In marketing, the postmodern perspective, as described by Baudrillard and Derrida, has been adopted by Firat et al. (1995) to distinguish three relationships between marketing and postmodernity. In the first relationship, marketing is seen as undergoing some transformations as a result of the impact of postmodern society. In the second, marketing is seen as a primary engine of change in the ongoing transition from modernity to postmodernity. In the third, marketing and postmodernity are seen as identical. Cherrier and Murray (2004) conclude, "In the post-modern era, there is no longer an attempt to refer back to nature or ground the representamen" (p. 513). Venkatesh et al. (2006) conceptualize "the market as a sign economy" (p. 258). Given these abstractions of information and service, there is now the challenge of reconnecting IT-related innovation and service with the real world. In this vein, Giddens (1991) argues for a reembedding of these systems, moving away from separation and division and toward togetherness and integration of matter, systems, work, humans, and their practices.

\section{Realms of Practices}

"As a theoretical paradigm, practice theory is still a relatively unsettled intellectual landscape with multiple sources, influences, and instances. As such, there is no definitive cannon of practice theory that is widely accepted by most scholars," state Feldman and Orlikowski (2011, p. 1241). The authors have identified three approaches of research on practice and practice theory: empirical, theoretical, and philosophical, referring roughly to the what, how, and why of practices. Although we will explain our understanding of practices (what), we are concerned with how practices support the understanding of signs and how they are used as resources. Other approaches using practice theory have analyzed how practices influenced the emergence of structures in organizations (Orlikowski 2000) and the emergence of markets (Kjellberg and Helgesson 2006, 2007). Although these are not the focus of our interest, these approaches do provide insights and assist in understanding innovation in society. For instance, Orlikowski (2000, p. 404) theorizes and studies "how people, as they interact with a technology in their ongoing practices, enact structures which shape their emergent and situated use of the technology." This process of "technology in practice" (Orlikowski 2000) leads to the institutionalization of certain practices. However, that stabilization is only temporary because new technologies and practices can and will emerge. In brief, innovation is a structuration 
process (Orlikowski 1992) where technology arises from human actors who are also shaped by the technology they create while the technology becomes institutionalized, which in turn influences human actors; this process continues over time, making it dynamic. The theorizing of Kjellberg and Helgesson $(2006,2007)$ can similarly help the innovator understand how markets can emerge, especially with discontinuous or radical innovation where behavior and usage patterns are dramatically altered. In this regard, Lusch and Vargo (2014) draw upon Kjellberg and Helgesson (2007) to discuss how markets are cocreated through integrating, normalizing, and representing practices. It is important to note that integrating practices are heavily influenced by technology in practice (or the actual use of technological artifacts).

In our theorizing we focus on how practices support our understanding of signs and how they are used as resources. In this vein, theoretical reasoning from five disciplines supports the idea that understanding is embodied in some manner in practices. These include philosophy and linguistics (Lakoff and Johnson 1980, 1999), social psychology (Gergen 1991, 1994, 1999), neuroscience (Boulenger et al. 2009, D'Ausilio et al. 2009, De Jaegher and Di Paolo 2007), computer science (Knott 2012, Nolfi and Mirolli 2010), and biology (Maturana and Varela 1987).

Lakoff and Johnson $(1980,1999)$ mainly argue that we live by the metaphors we use and that these metaphors are taken from the "reality" from the activities performed in particular. We can only give some examples of the rich elaboration of Lakoff and Johnson (1980), such as "for example, the entailments of LOVE IS A COLLABORATIVE WORK OF ART arise from our beliefs about, and experiences of, what it means for something to be a collective work of art" (p. 139, emphasis in original). The practice of a collaborative work of art is the practice referred to by explaining the word "love." As an example of the practice of a movement, they argue that changes are movements: "She fell into a depression," "He went crazy," "Her speech moved the crowd," "Their negotiations pulled both sides from the brink of war," and "The news propelled the stock market to record heights" (Lakoff and Johnson 1999, p. 442 et seq., italics in original); all of these descriptions are based on human practices that serve as a meaning giving reference. Other descriptions refer to the practice of a journey. Lakoff and Johnson (1980) argue that "an argument is a journey," they and give the following examples: "When we get to the next point, we shall see" or "we will proceed in a step-by-step fashion" (p. 90, italics in original).

Constructionists such as Gergen (1994) extend Derrida's deconstructionist thoughts by integrating different forms of practices: "Deconstructionists tend to confine their analysis to the world of texts, but if we extend the implications of such analyses, we open new alternatives in the social domain. . . . Let us press the analysis outward to a 'world' beyond texts. . . What prevents us from introducing what we call 'actions' or 'objects' into the domain of textuality (as signifiers)? The play of signifiers is essentially a play within language, and this play is embedded within patterns of human action" (p. 262). Patterns of human actions are practices; hence, in this view, the "sign play" is embedded in practices.

In computer science, Knott $(2012$, p. 2) claims that "the semantic structure of a sentence reporting a concrete event in the world can be understood, at least in part, as a description of a sensorimotor process - namely the process involved in experiencing the event." And "that certain parts of a model of natural language syntax are also straightforwardly part of a model of sensorimotor cognition." These sensorimotor cognitions reflect that practices are performed and somehow embodied. Or we can consider the practices we engage in in everyday discourse, and that we can especially see as a young child matures. We often ask children to name an object (i.e., show them a box and see if they call it a ball), we may ask them in situations where an object may have many meanings to guess at the meaning (i.e., show them a person crying and ask them to guess at what is meant), or we can ask them to act in a certain way and then observe whether the action occurs (i.e., ask them to sit down). In each of these practices 
(naming, guessing, and acting), we can never be sure that what results reflects a successful communication or some other fact (e.g., the child is trying to deceive or simply be stubborn and disobey). However, parental practices that are also embodied in the context of human interaction between child and parent often provide a more complete answer. These practices, or what can be thought of as "language games," are used to model the formation of language in artificial embodied agents (Loreto et al. 2010, Steels 2010) in computer science.

We do not discuss neuroscientific or biological research on signs and practices here. However, the cited literature supports the general idea that practices support the understanding of signs as we will discuss below.

\section{Toward an Understanding of Signs and Practices}

\section{Practices as an Indispensable Counterpart of Signs}

Inventions and innovations, or new technology, are grounded either explicitly or tacitly (Polanyi 1962) in propositional knowledge or how things work the way they do. At some point, this propositional knowledge is translated into prescriptive knowledge and becomes the basis of the technology that supports innovation (Mokyr 2002). Propositional and prescriptive knowledge is largely represented by signs and sign systems. In addition, prescriptive knowledge and the technology it supports are always based in practice. We now elaborate more on the nature of signs and practices.

Using Signs. We define signs as something perceivable, something people become aware of through their senses. A sign is distinguished from its environment; otherwise, it would not be perceived as a sign. People also perceive a sign and the environment simultaneously and can identify a sign because of its difference in relation to its environment. According to SpencerBrown (1969), a sign is the marked side of a distinction. A distinction is a precondition or part of conscious perception. Whenever we see a car, a tree, a letter, or a word or phrase, we perceive it because of its difference (distinction) from its environment, and then we take one side of the distinction and call it "car," "tree," "letter," or "word or phrase." Subsequently, we connect the idea of distinction with the theory of practices.

Many service situations are characterized by a non-face-to-face interaction between the service provider and service beneficiary. This is true for online banking, automated teller machines, check-in kiosks at airports, interactive voice response from artificial agents, packaging labels, and even the numerous manuals that need to be read several times over to understand them. In non-face-to-face interactions, the notion of interaction is very often reduced to writing and reading - that is, reduced to signs and their "understanding." Signs are valuable when they support some kind of order, whether this is giving an orientation, getting an overview, or helping someone act. Thus, signs only render service if the user has learned to understand them. In line with social system theory (Luhmann 1995) or social constructionism (Gergen 1991, 1994, 1999), using signs is here understood as an operational mode. An operational mode is an ongoing process that may or may not be carried out by individual humans. However, the unit of analysis is not individuals or human states scuh as feelings, motivations, or emotions; the units of analysis here are two ongoing separate modes of operation (processes): one that uses signs and another that uses practices. We now distinguish three realms in which the use of signs can be helpful (Löbler 2010): interaction, language, and thinking.

Interaction is the coordination of behavior by the use of signs. Learning or understanding a sign means being able to relate it to behavior according to its meaning. For example, simple 
things in daily life such as a traffic light, a calendar with scheduled activities, and an airline schedule can be viewed as coordination mechanisms that help people manage their dependencies on other drivers, other people, and the airlines, respectively.

If an actor were isolated from other humans, such as on an island with no physical or virtual contact with others, he or she would not need to use signs to coordinate behavior. Rather, the person may use signs on an island for purposes other than coordinating behavior, such as to remember things. Notably, not only do signs coordinate people's behavior, but they also coordinate the signs themselves, as one uses signs to describe signs and words to describe words. This is a topic we turn to next.

Language is mainly the coordination of signs. People also use signs, words, and language to discuss and clarify the meaning of specific words: "Very often we only have other words to express the meaning of the word in question" (Löbler 2010, p. 223). Thus, people use words to coordinate the use of other words. Consequently, signifiers are arbitrary (de Saussure 1959); this does not mean that they are individually arbitrary, but rather that they are arbitrary in the way a society or culture uses them. Thus, the second realm of signs as service is a realm of coordinating the use of these signs. As such, signs used in the coordination of meaning are always in reference to the relation of actors or people who use the signs. People also use signs to coordinate sign operations such as thinking, a topic we now briefly discuss.

Thinking is an activity of operating with signs. The third realm of signs relates back to Wittgenstein (1960, p. 6): "Thinking is essentially the activity of operating with signs." Thus, thinking can be understood as the coordination of operations with signs. This does not mean all thinking forms are coordinated by a common language; architects, engineers, and mathematicians use their own system of signs for thinking. Signs are everywhere, whether they are digitized or not. However, for digitized signs in particular, people must transform or reembed them into real life. We argue that embodied experience and digital artifacts (e.g., signs) are linked together by practices.

Using Practices. Considering that signs are used in coordinating interactions, language use, and thoughts, the question arises: How do we know how to deal with signs, or more simply, how do we know what the signs mean? Understanding as something that is embodied suggests that meaning not only is mostly implicit but also coincides with practice theory (Reckwitz 2002; Schatzki 1996, 2007) and the literature presented above. We use social practice theory (not just practices or types of practices) as a reference to the embodied source of meaning.

Practices are implicit and embedded in culture and cultural knowledge. According to Schau et al. (2009, p. 31), "Practices are linked and implicit ways of understanding, saying, and doing things." Practices serve as a means for implicit coordination (Espinosa et al. 2004, Toups and Kerne 2007). In other words, "A practice is thus a routinized way in which bodies are moved, objects are handled, subjects are treated, things are described and the world is understood. This way of understanding is largely implicit" (Reckwitz 2002, p. 249).

For Giddens (1984, p. 2), practices are the basic unit of social research: "The basic domain of study of the social sciences, according to the theory of structuration, is neither the experience of the individual actor, nor the existence of any form of societal totality, but social practices ordered across space and time." Thus, practices coordinate the way people operate with signs, but because practices are usually implicit, people often take them for granted. A practice is "a way of cooking, of consuming, of investigating, of working, etc." (Reckwitz 2002, pp. 249250). It is a way of doing things and also a way of expressing ideas, thoughts, entities, and processes into words and signs. Usually, people do not realize they do something in a specific way because the act is mainly implicit and routine and taken for granted. 
Practices are the "context" in which signs are embedded. This argument relates back to Wittgenstein (2008, p. 43), who states that "the meaning of a word is its use in the language," and its use in the language is a practice. The relationship between the intelligibility of signs and actions/doings/practices is an important one-but one that has often been neglected or taken for granted and, thus, not totally understood. Relatively recently, we have witnessed an interest among IT scholars in using practice theory to understand complex IT systems (Burford 2011, Nathan 2012, Rosenbaum and Shachaf 2010, Srinivasan 2007, von Krogh et al. 2012) and to understand the use of technology (Orlikowski 2000).

Using Signs and Practices. Going back to the realm of signs, we can underpin explicit coordination by a second domain that is implicit - namely, the domain of practices - and practices can be understood as an indispensable counterpart of signs to cocreate meaning. Note that signs and practices are two sides of the same coin - the coordination in a societal reality.

In the realm of behavior, an explicit sign — for example, a red traffic light—only coordinates behavior if it is understood. Understanding in this case means reference to a practice. The behavior we have learned to perform at a red traffic light is the act of stopping. So using signs can only coordinate behavior if it is referred to practice or if the practice is referred to the sign usage. Here, we can use Bateson's (2000, p. 460) notion of "the difference which makes a difference." The red light is distinguishable from a green light, but this will not mean anything if this distinction is not linked to a second distinction-namely, stop or go. The (learned) practice links the first and second distinctions so that meaning can emerge.

Regarding linking signs and practices, the same pattern occurs in the realm of language use. For example, people know how to use words in their specific language (e.g., German, French, English) because they "operate" according to the grammar of these languages. Before they have learned to read or write, children use their mother tongue, though they have not learned the grammar explicitly; rather, they have learned the grammar implicitly, meaning that they do not know they know it. Later, after having learned how to read and write, they know about grammar, but this knowledge is mainly implicit and thus taken for granted. In this sense, grammar is a practice used implicitly, but people can also explicate the grammar by using words according to this grammar to describe this grammar. The grammar here is self-referential; if people do not have it, they cannot use it, and vice versa. Thus, the grammar is the practice of how to coordinate the words; it is implicit, but the words are explicit, and together they constitute the domain of language use. In addition to grammar, many other practices operate through the use of words - experts use words differently than lay actors, suppliers may use words differently than their customers, different departments in a company may use words differently, and so on. In each case, people are not always aware that they use words differently because their use is based on different practices, which are mainly implicit.

In the realm of thoughts, people operate with signs (Wittgenstein 1960), but how they operate is again the domain of practice. People think differently, and the result of this process is expressed in words, equations, pictures, or other sign systems. The way someone thinks is mainly implicit, but what he or she thinks about is explicit; otherwise, he or she could not consciously experience thinking. Thus, the explicit way of using signs in the three realms is complemented by implicit ways of operating with these signs. Figure 1 shows how explicit coordination is embedded in or based on implicit practices.

We now incorporate the distinction of using signs and practices into service and IT-related service, in particular by using service-dominant logic. Here, signs and practices become resources for service provision. 
Figure 1. Explicit Coordination Level Embedded in Implicit Coordination (Adapted from Löbler 2010)

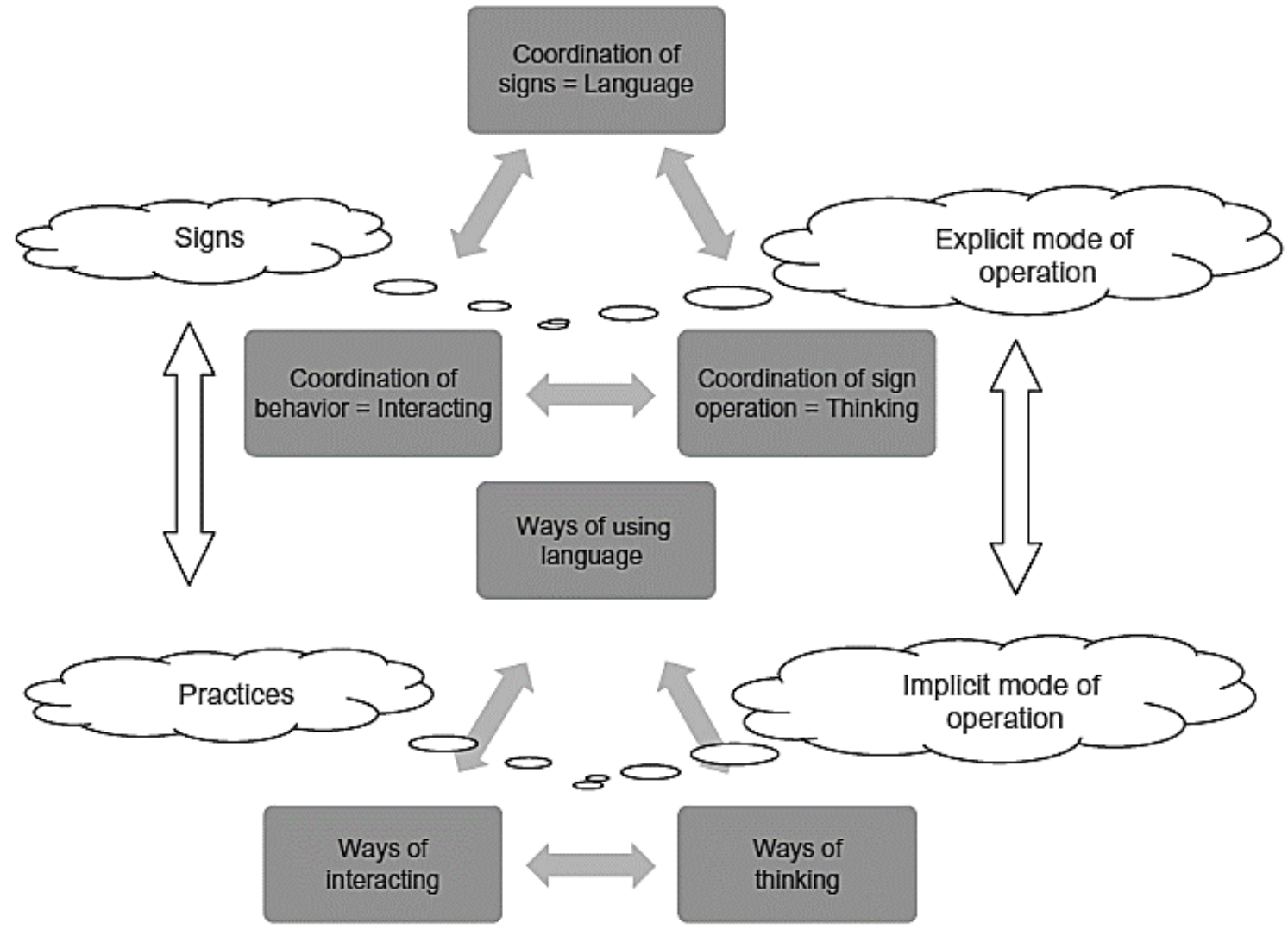

\section{Signs and Practices as Resources in IT-Related Service Innovation}

Although business scholars (Berry et al. 2006, Michel et al. 2008, Ordanini and Parasuraman 2011, Sawhney et al. 2005) are finally focusing on service versus goods innovation, there is a much broader interest. This includes economics (Cainelli et al. 2006, Gallouj 2002, Gallouj and Suvana 2009), strategy (Dorner et al. 2011), and information systems (Fichman et al. 2014, Nambisan and Sawhney 2007, Sheehan 2006, Swanson 1994, Yoo et al. 2010). Importantly, some argue that service innovation is distinct from product (goods) innovation and thus new theories and frames of reference are required (Edvardsson and Olsson 1996, Fitzsimmons and Fitzsimmons 2000, Kallinikos et al. 2013). However, others argue that an integrative framework that includes services and products and thus avoids the goods-services divide is needed; these studies try to modify current innovation models to the service innovation arena (Nijssenet al. 2006). In this regard, Vargo and Lusch $(2004,2008,2011)$ would argue that service-dominant logic can provide a unifying innovation framework because it views all innovation as based on the novel integration of resources to support value cocreation.

All service innovations arise from signs and practices, which become resources to provide service. Practices are ways of doing. In performing a particular practice, one may notice a pattern and then may name the pattern. For example, we say "googling" or "tweeting" in English or "googeln" or "twittern" in German for these new practices. However, as soon as we try to describe precisely and clearly what we mean by these words, we have trouble doing so because we cannot totally explicate an implicit practice. In this sense, signs indicate practices, and signs are meaningless if the practice is unknown. So practices are present before we use signs to indicate them, and thus developing the ability to sense practices and trying to understand or perceive them are important sources of inspiration that lead to ideas for innovation. From a business perspective, customer practices cannot be understood by simply 
looking at the signs used. Signs indicate different practices for different people. Firms must also understand or experience customer practices, especially if they want to support or offer substitutes. For instance, when surgeons switch from traditional to robotic assisted surgery, it is important to understand the surgeons' experiences in such things as how to move their wrists and then to use this information to design better training programs, usually with computer simulation, for the surgeons.

Service-dominant logic defines service as the application of resources for the benefit of another party. It also makes the important distinction between operand and operant resources (Vargo and Lusch 2004). Operand resources (from the Latin operandum, meaning "something that must be worked on") are resources that undergo an act or work. Conversely, operant resources are resources that do an act or work (Constantin and Lusch 1994). Operant resources include applied skills and knowledge. Whenever people act, they require some kind of skill or knowledge, so they always act as an operant resource. However, the service is not the skill or the knowledge; it is the application of that skill or knowledge. By applying operant resources, people use some operand resource, whether it is the air they breathe, the tool they use, or a thing they change. So whenever people act, they use their operant resources along with operand resources to create something. This thinking is consistent with the Vargo and Lusch's (2008) service-dominant logic foundational premise FP9, which views all social and economic actors as resource integrators. When actors integrate resources, they often arrive at novel combinations that result in innovative ways of doing.

It is important to realize that the process of combining or integrating operant and operand resources is undertaken not only by the service provider but also (sometimes simultaneously) by the service user (beneficiary). Orlikowski (2000) emphasizes the role of the service beneficiary versus technology artifacts when trying to understand technology-in-practice. Although using a different lexicon, she has shown that operand and operant resources influence the use of information technology.

Consider, for example, word-processing software as a service. The program designer and writer have applied their skills and knowledge (operant resources) to create and produce the software (operand resource). Now, the user needs his or her skills and knowledge (operant resource) to use the program (operand resource); otherwise, it has no value (value-in-use). In addition, the service provider and user are only linked by signs. The user does not explicitly see the program's operations but rather only the result in the form of signs. What users often must do is to infer the operations from the results of these operations, which they see. In contrast, the service provider must imagine or foresee the operations the user may want to execute with the program. Both the program's and the user's operations are implicit practices. The program's operations are implicit for the user, and the user's operation is implicit for the service provider. The more parties know about each other's practices, the better understood and used the software program.

Thus, an IT-related service connects or integrates practices by the use of signs, and by doing so, practices become resources, something an actor draws on for support (von Krogh et al. 2012). Grönroos (2008) and Sheth et al. (2000) mention practices from the perspective of service-dominant logic, but they do not use the term in the same vein as Schatzki (1996) and Reckwitz (2002), who follow Wittgenstein's (1960) understanding of practices as implicit ways of doing. Rather, they use the term as a synonym of doing. Reckwitz emphasizes the different meanings using the German words "praktiken" and "praxis" (as a synonym for doing). Note that the term "practices" ("praktiken") as understood in practice theory has a very different meaning than practices in the vein of praxis, which is simply what is done. Löbler's (2010) analysis of signs and practices (also in accordance with service-dominant logic) follows the meaning of practices in the sense of praktiken. Similarly, in their study of how brand 
community practices collectively create value, and consistent with value cocreation in servicedominant logic, Schau et al. (2009) adopt the perspective along a praktiken concept of practices. Thus, it is not just simply what people do, but it is a theoretical approach to practice that stands in contrast to individualist ontologies and where social phenomena are understood as mainly societal facts, structures, and systems that resist reduction to individual actors (Araujo et al. 2008, Löbler 2011).

Of these authors, only Schau et al. (2009, p. 35) identify practices as resources, stating that "resources may compose cognitive elements of practices (e.g., knowledge of procedures and rules), status elements (e.g., self-esteem), and emotional elements of practices (e.g., commitment, pride)." In addition, they argue that "practices endow participants with cultural capital" (p. 38) and that "practices create value" (p. 39). We argue that the view of practices as resources is underplayed in their work and mostly ignored in other work in marketing related to practices. In addition, practices have not been discussed as resources in IT-related service innovation, though these practices (in the vein of praktiken) are very important in service and IT-related service in particular because they are the counterpart of signs and serve as meaning providers of signs.

We illustrate this in a nondigital world with an example now common in the IT world. Consider the now familiar computer "desktop," which is commonly used as a user interface for interacting with the internal computer or IT world. It was not always this way. A computer desktop is kind of a simulation of a real desktop. It works as a user interface because people were familiar with desks and using their desktops to work with and arrange their papers and other items. Using a desk and its desktop was a practice long before computers. The first personal computers did not even have desktops, with user interaction done solely through symbols (signs) on a command line. Apple introduced the desktop to personal computing in the 1980s, adapting a method pioneered by Xerox for business computing (Smith et al. 1982; see also Erickson 1990). People could suddenly use existing practices (working on a desktop) as resources when working with a computer. The computer desktop is simulated by signs, which can be embedded in real-world practices. So both the signs and the practices become resources. In this case, people can intuitively use IT because its use is based on practices. The intuitive uses are always practice based but are not always explicit. If practices are integrated, they become resources. Moving documents on a touch screen feels almost identical to moving items on a real desktop- just touch the document icon and move it using an implicit practice that we are all used to, but not always aware of. These kinds of innovations integrate practices and signs: the practice becomes operative by moving fingers like touching a document and then drawing it up or down. The signs (on the screen) create or simulate the impression that the documents are really moving.

Importantly, however, practices are connected through signs, and signs are connected through practices; the explicit (signs) is connected to the implicit (practices), and vice versa. One part of the service innovation in the digital world can be defined as creating new signs or combining signs in a new way with the aim of creating new forms of coordination (i.e., new ways of interaction, of language use, or of sign operation or thinking). But this is not yet a service. Rather, it is an innovative service if it is actually used by others in the practical context. Thus, service and especially service innovations must be embedded in the beneficiary's practices because these practices become resources in value creation (Schau et al. 2009).

\section{IT-Related Service Innovation}

Service innovation is increasingly being driven by systems for sign usage, which makes signs more the foundation for service provision mechanisms. Because signs are increasingly 
accessible to all actors, the level of innovative entrepreneurial activity in relation to sign usage will accelerate over the next decade, and therefore it is important for information technology and innovation specialists to understand signs and sign systems and how they link to practices.

\section{Illustrating Service Innovation}

To understand service innovation, it is important to understand humans as resource integrators (Vargo and Lusch 2008) who seek ways to relieve themselves of certain tasks and ways to enable them to perform tasks (Normann 2001). Driving a car, riding a bicycle, or walking is part of a larger resource integration effort, and this effort can consist of many relieving and enabling innovations (tools) (Normann 2001). For example, an automobile could have digital signal processors built into it that allow it to recognize traffic lights and bring the automobile to a stop when necessary, thus relieving the driver of this activity. At the same time, the automobile could be linked to a satellite geographic positioning system, which enables the driver to spot potential traffic problems ahead and reroute to avoid the red light.

Table 1 illustrates how various IT-related service innovations have enabled humans to better coordinate explicit, but abstract, sign systems to support the implicit coordination of practices. Recent service innovations, including surgical telemedicine, Facebook, and YouTube, have used new signs, new configurations of signs, and their processing to make their customers' practices easier, richer, more knowledgeable and skilled, and, in short, better. All these examples use signs to coordinate signs (i.e., language use), coordinate behavior (i.e., coordinate ways of interacting), or coordinate sign operation (i.e., how actors think).

Furthermore, each of the IT-related service innovations in Table 1 offers a compelling value proposition. We will describe the process of writing as a part of word processing as an example in detail in the next section. In summary, signs in the form of words and phrases get their meaning through the practices with which they are associated. Service innovations help people do what they are in principle able to do on their own and thus relieve them (Normann 2001), but they also help them do things they are not able to do on their own (use a GPS service to avoid traffic delays) and thus are enabling (Normann 2001). Word-processing systems, like all IT-related service innovation, have these two sides: they are signs (otherwise they could not be digitized), and they relieve or enable people's activities (otherwise they would not create value). The activities are carried out by people on the implicit basis of practices, thus becoming resources.

\section{Paths of Service Innovation}

The distinction between signs and practices allows describing paths of IT-related innovations as well as understanding which innovations are incremental or disruptive/radical and why. We adopt the classification that Robertson (1967) developed: continuous, dynamically continuous, and discontinuous. With a continuous innovation, the existing product is modified but there is no altering of current usage and behavior patterns. In the case of dynamically continuous innovations, some altering of usage and behavior patterns is required. Discontinuous or radical innovations are disruptions in established usage and behavior patterns.

As in Norman and Verganti (2014), we refer to incremental innovations as being improvements within a broad representation or mental model, and we include continuous and dynamically continuous innovations. With discontinuous innovation, the mental representation or model is changed. The representation is our schema for interpreting and understanding the practice behind doings, the implicit way of doing. Stated alternatively, an continuous (incremental) innovation does not change our representation for doings, whereas a 
discontinuous (radical) innovation changes our representation for doings that either creates a new practice or integrates an old one in a new way. Discontinuous or radical innovations are disruptive because they drive the creation of new markets or value constellations (Christensen 1997). A new practice was, for example, generated with the invention of mechanical typewriters and hence a new market. Typewriting was simply not existent before typewriters. Or, the ability to write on a tablet's screen with a pen-like device is an integration of an old practice (handwriting) into a new technology and thus can be viewed as dynamically continuous (i.e., there is some, but not a major, alteration of usage and behavior patterns).

Table 1. Examples of Successful Digital Service Innovations

\begin{tabular}{|c|c|c|}
\hline $\begin{array}{l}\text { Digital service } \\
\text { innovations }\end{array}$ & $\begin{array}{l}\text { What explicit signs are digitized to } \\
\text { coordinate }\end{array}$ & Implicit coordination of practices \\
\hline Word processing & $\begin{array}{l}\text { Writing: Words are digitized to } \\
\text { be stored, repeated, and so } \\
\text { forth. }\end{array}$ & $\begin{array}{l}\text { Words and sentences can be rearranged; their style } \\
\text { can be changed. Writing and rewriting are much } \\
\text { easier. The practice of writing is supported with } \\
\text { digital tools such as dictionaries, grammar } \\
\text { guides, and Web resources. }\end{array}$ \\
\hline Spreadsheet & $\begin{array}{l}\text { Ordering and calculating: } \\
\text { Numbers are digitized to be } \\
\text { stored, repeated, and connected } \\
\text { to calculate. }\end{array}$ & $\begin{array}{l}\text { Calculations of different kinds can be performed } \\
\text { easily and with less knowledge and skills. Signs } \\
\text { can be connected and used in calculations. } \\
\text { Calculating practice is supported with many } \\
\text { digital tools, such as mathematical formulas, } \\
\text { graphing and other visual displays, and } \\
\text { statistical tools. }\end{array}$ \\
\hline Calendar & $\begin{array}{l}\text { Scheduling: The reliance on } \\
\text { handwritten calendars to keep } \\
\text { track of appointments is } \\
\text { reduced, and a digitized } \\
\text { calendar enables links to other }\end{array}$ & $\begin{array}{l}\text { The planning and organizing of day-to-day } \\
\text { activities, and integrating those with other } \\
\text { actors, is made simpler. It enhances the practice } \\
\text { of time allocation and time trade-off and } \\
\text { priority setting. }\end{array}$ \\
\hline
\end{tabular}

PowerPoint

Database management

Email

Web search engine

Surgical telemedicine

Facebook

YouTube

IBM Smarter Planet (Stockholm)
Searching digitized data: The ability to access trillions of signs (data, information) and find relevant but digitized information.

Digitizing hand movements.

Interfacing actors: Interface between actors via digitizing the connection of people.

Displaying or showing videos to the "globe": Digitized visualizing experiences, events.

Moving transport vehicles: Digitizing traffic movements and flows.
Digitizing the practice of drawing enables people to "draw" (making or showing pictures) who could not previously. The practice of expressing ideas through visuals, color, and design is enhanced.

Easier organization and handling of huge amounts of data, supporting the practice of organizing data to create information and insights.

Practice of coordinating with others through lean communication becomes easier and quicker. The practice of writing is supported. In addition, sending and receiving letters has no relevant direct cost. The practice of postal service is digitized, and people perform this service for themselves.

Research and search is made much easier while it is restricted to the digitized world. People do more research and search because of such ease. People are able to see more connections and thus be more creative.

Surgeries can be performed long distance through hand-moving transfer, expanding the practice of surgeries in geographic space and bringing together diverse experts.

An interchange of "news" and other information with "friends," community-building practice and the ability to stay in touch is enhanced.

Interchange of "experiences" and other events with "friends" and public that enhances the experience of "sharing."

Signals are set so that practices are changed and traffic jams are avoided, making traffic more convenient, enhancing the practice of mobility. 
Figure 2 shows the pathways to IT-related innovation, using "writing" as a part of "word processing," along two independent dimensions: sign operations that are enabled by technology and practices that are integrated when these technologies are used. Writing is a well-known practice performed by using material such as paper and an instrument such as a pencil as resources operating with signs. There were some continuous and dynamically continuous innovations throughout history, such as different types of ballpoint pens and fountain pens; however, these innovations did not change the practice of writing (indicated by arrow 1 in Figure 2) but made it easier. The invention of the mechanical typewriter instead was discontinuous or radical, as it changed the practice of writing (indicated by arrow 2 in Figure 2). People had to train to use mechanical typewriters. To exercise this practice was part of secretaries' education. Then electronic typewriters were introduced, which was again a dynamically continuous innovation (indicated by arrow 3 in Figure 2). It did not change the practice of typewriting in principle, but it required the typist to learn the sensitivity of the keys on the typewriter so as to type faster and more effectively. Then a discontinuous or radical and disruptive change was the introduction of personal computers with (first primitive and later advanced functions, as continuous innovations) word-processing software (indicated by arrow 4 in Figure 2). Although the practice of typing remained, the whole practice of writing changed as it enabled copy, paste, and delete, etc., behaviors. Texts now could be rearranged easily, and the correction of a misspelling was no longer issue. Next, a discontinuous or radical and disruptive change arrived with speech recognition and the processing of recognized words and text (indicated by arrow 5 in Figure 2). This again is a different way of "writing," a different practice, as this software allows seeing the text directly on the screen as soon as it is dictated. The writer now is a speaker who watches "an invisible hand" write text on the screen; a totally new experience emerges, and with it, a new practice. One has to get used to this new practice. Currently, the next step in this evolution is translating software, which is still primitive, and many design challenges need to be overcome because of implicit knowledge, and with that implicit language, practices. 
Figure 2. Word Processing Innovation Pathway

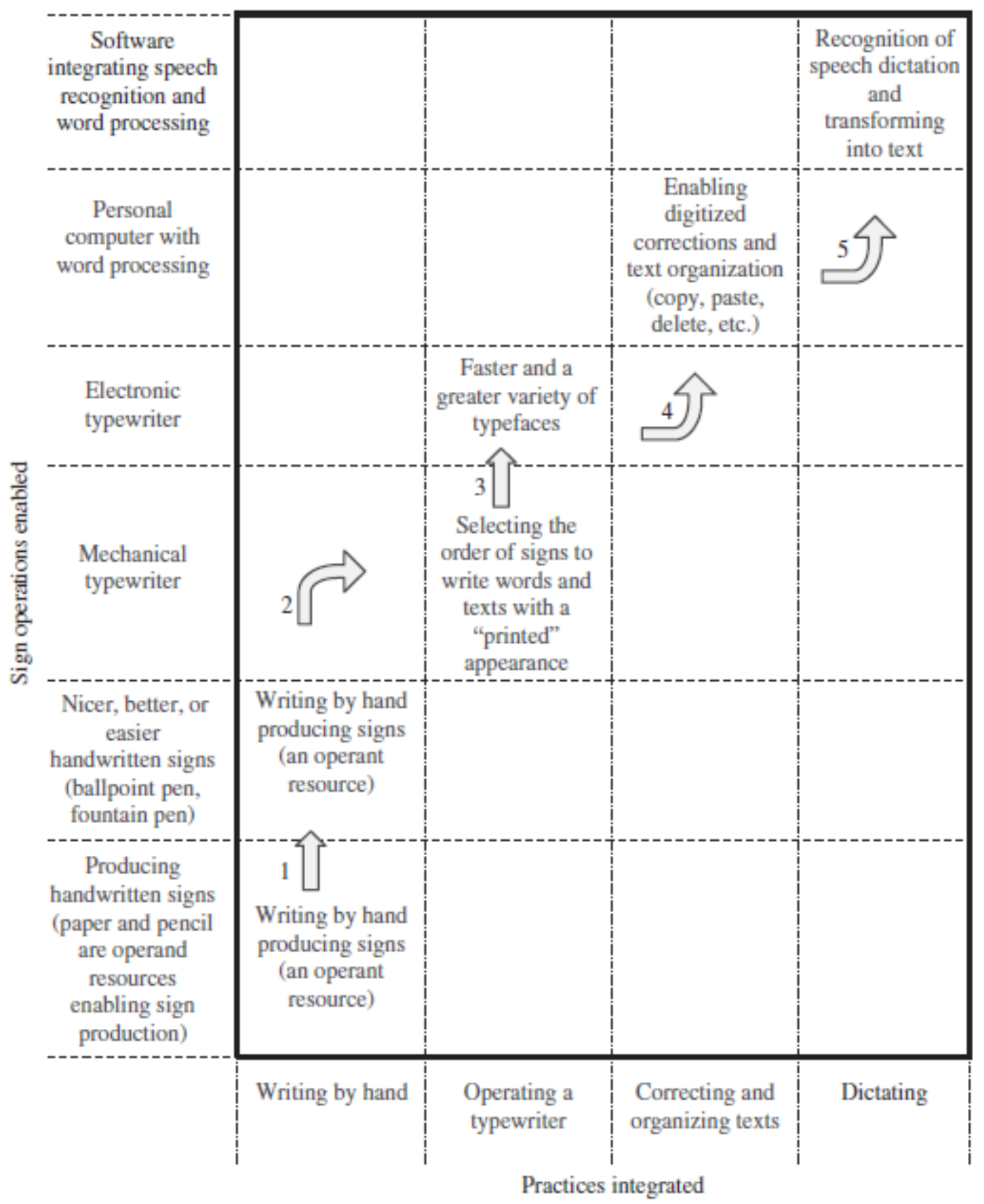

Another example of innovation pathways is video games, as shown in Figure 3. Early video games were consoles connected to either a TV or other screens: "The user interface required expertise, which took considerable time and practice to acquire" (Norman and Verganti 2014, p. 85). Hence a new practice was born: playing video games, indicating a discontinuous or radical and what became a disruptive innovation. Graphics were weak and "grainy." Then several continuous innovations improved the graphics and the overall appearance of the scenes. Next, high-speed Internet allowed integrating several players online, which integrates a kind of playing with others known as massively multiplayer online games and massively multiplayer role-playing online games. With the introduction of the Nintendo Wii console, the next discontinuous or radical disruptive innovation appeared, and the market expanded, allowing anyone to play sports games either alone or with others without expert skills. The integration of body movements as a practice and resource into "video games" was a major change in behavior and usage. Another way of integrating body movement is implemented by the Xbox Kinect motion controller, which uses gesture recognition to allow players to control game 
movements. However, all the advanced video games lack the feeling of force feedback as one experiences it when playing with a piece of sports equipment. This is a possible path for discontinuous or radical innovation. It is already used in airplanes so that pilots can "feel the pressure" on their control sticks. It is also used in the experience of using a game joystick. Building in a force feedback technology in video sports games can create a large market. A further step of IT-related innovation can be seen in integrating force feedback into games played with others.

Figure 3. Video Game Innovation Pathway

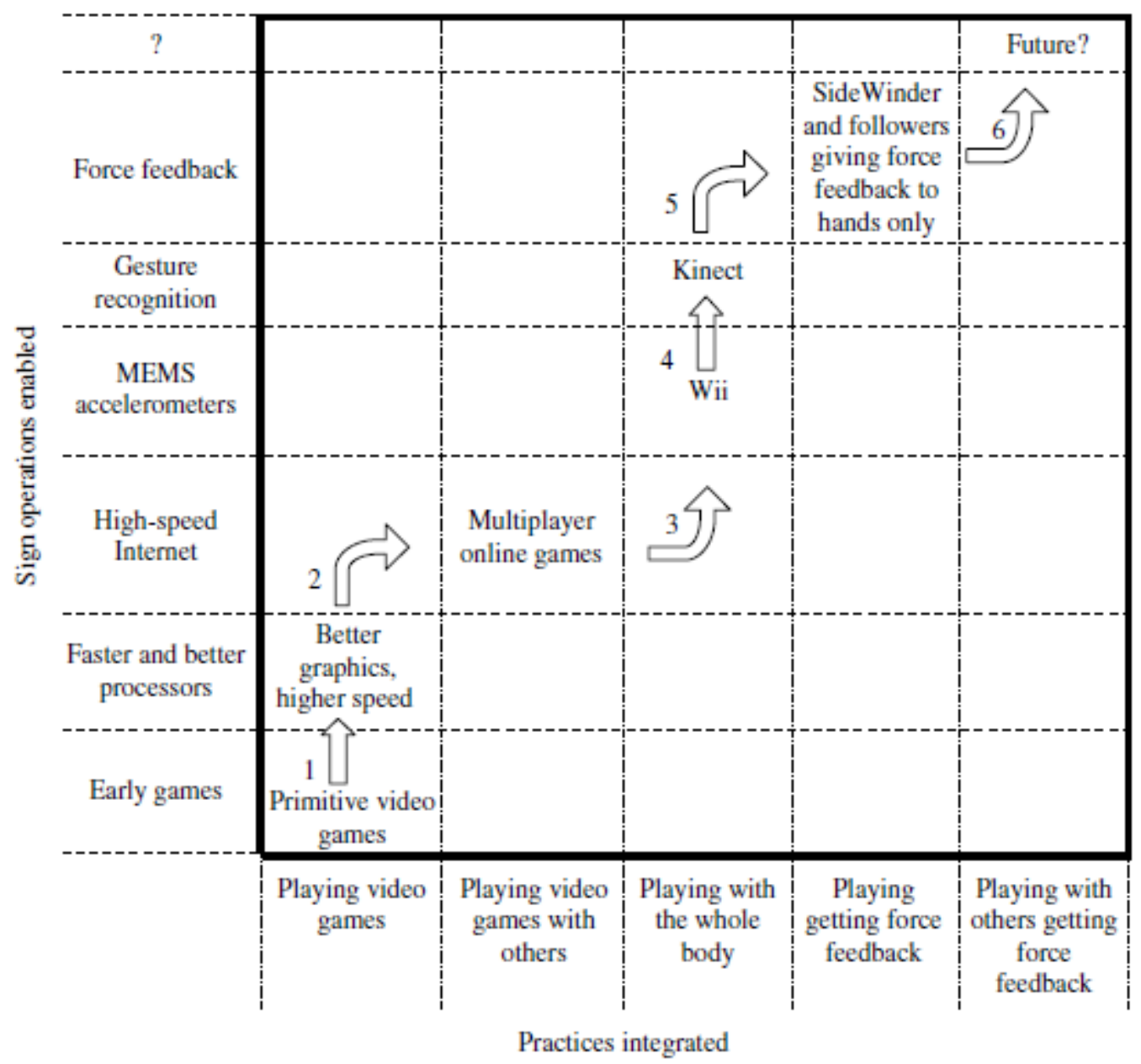

Note. MEMS, microelectromechanical systems.

The video game example shows that all practices existed in some earlier form prior to the new technology. Many innovations just integrate these new ways of playing as resources into video games. People have always played with something, and they like to play with others. When playing bodily engaged games, they feel the forces of the playing tools (tennis rackets, golf clubs, etc.). And when playing bodily engaged games with others, they feel their movements. The better the practices of playing are integrated as resources, the better the innovations. 


\section{Future IT-Related Service Innovations}

IT-related service innovations must positively affect people's everyday activities and actions, which are based on implicit practices that provide meaning. Unsuccessful digital service innovations are those that do not sufficiently enhance practices and thus are not viewed as valuable. Signs themselves are not the pathway to service innovation in the digital era. However, developing an understanding, through research or other means, of the explicit coordination by using signs through abstract sign systems connected by enhancing the implicit practices of human actors can provide many ideas that can form the basis of digital service innovation. This is especially the case when digital artifacts are embedded in a larger ecosystem that is constantly shifting (Kallinikos et al. 2013). This can be further supported by viewing a practice, in this ecosystem, as a complex adaptive system (Burford 2011).

According to service-dominant logic, people should not begin with the things they are trying to invent or innovate around, because this conveys the goods-dominant perspective (Paswan et al. 2009), which is neither user centric (Michel et al. 2008) nor practice centric. Servicedominant logic begins with a focus on the actor as a social and economic resource-integrating actor who always cocreates value with other actors but who also uniquely and phenomenologically determines value from their perspective (Vargo and Lusch 2004, 2008). Because, as we have argued, practices are resources, it follows that actors integrate practices. No practice stands on its own but lies in a web of social and economic networks interfacing and integrating to varying extents with other practices. Consequently, this process begins to create a canvas for service innovation and how it emerges and proliferates aligns with the call by Kallinikos et al. (2013) to view digital artifacts as editable, reprogrammable, interactive, and distributable.

Thus, IT-related service innovation can be facilitated by recognizing that skills and knowledge can be applied (in digitized ways) independently of time and place on the one hand but embedded in practices on the other hand. In the digital age, actors around the world become increasingly physically free to choose where and when to apply skills and knowledge in digitized ways. This will allow new coalitions of actors, each bringing resources, to form and cocreate innovative service offerings. Out of this will be a rapid growth of service innovation.

In a digital age, practices must be discovered, named, and then supported by a service (all the steps necessary for digital service innovations). The mapping of these practices is an area ripe for further research but may not be fully achievable because of the implicit nature of practices. Nonetheless, the study of practices in different contexts and/or cultures might be the precondition for successful IT-related service innovations.

\section{Discussion}

The ideas presented on signs and practices as resources in IT-related service innovation set the stage for additional theory development. At the same time, we see the need for managerial and action research and offer a start at a research agenda.

\section{Theory Development}

Many suggestions for theory development and research arise from the pretheoretic framework presented. It is a pretheoretic framework because it offers a different (and, to our knowledge, new) ontology in the field of service innovations and IT-related service innovations in particular. This ontology consists of two complementary modes of operation: an explicit mode of operation and an implicit mode of operation. The usefulness of this ontology is likely to be 
a result of how well it is used to reshape concepts, ideas, and theories not only from marketing, computer science, and information systems but also from the social sciences, such as anthropology, communications, economics, psychology, and sociology. Since value of service usually unfolds while the integration of resources takes place, our process-oriented ontology may serve for a better understanding of the value-unfolding processes. Which explicit sign operations and which implicit practices support value cocreation? The operational mode ontology as proposed views value cocreation as dynamically emerging during a resource integrating process where the resource integrating process is "coordinated" by an implicit as well as an explicit mode of operation.

Taking the ideas and concepts presented and developed in this work, we suggest that there is a major need to improve our understanding of the emergence, nature, and scope of implicit practices and their connection to explicit ones. Implicit practices are often tacit practices that are difficult to uncover and, thus, to conceptualize, theorize, model, and, ultimately, use to develop service innovations. One potential area of research could center on why some actors (marketers, engineers, or inventors) are better able to identify implicit practices and use them as a basis to create IT-related service innovations.

The IT literature has begun to realize that implicit practices play an important role in digital service. For example, regarding security requirements, Houmb et al. (2010, p. 63) state that "security expertise and guidelines are not stated explicitly in the CC [Common Criteria]. They are rather phrased in security domain terminology and difficult to understand for developers." Consequently, new ways of eliciting implicit practices must be developed. However, these ways will also have limitations because there are "realities" out of reach of language, and thus they cannot be described with words. The efforts that have been undertaken to describe the indescribable result in simulacra. As described previously, Facebook and Twitter are good examples of simulacra: They create the reality they use, and they are very successful in doing so. They did not build on old explicit practices but, at the same time, were grounded in a long human evolution of implicit practices that supported the creation of new explicit sign operations.

In the unfolding, increasingly digital IT world, the material world does not disappear or diminish. Thus, there will be service in the digital world that solves "material" problems, such as traffic jams, natural disaster recovery, customer cues, impending failure of tangible products, and pollution. Here, it may help to elicit practices to better coordinate them with the use of signs. Some practical questions can only be answered with better theories of complex systems such as natural disaster recovery or global pollution abatement.

In addition, the proposed ontology understands the world not only as material "things" but as operational modes integrating these material entities as recourses. With this, it puts the dynamic of societal interaction in the foreground of service innovation. Service and, with it, service innovation, which unfold their value throughout the process of resource integration, need an ontology supporting the understanding of these process-related dynamics. We believe that the proposed ontology supports (among others) the following research needs: First, we need a better theoretical base around how humans invent and develop signs to be used to develop language and coordinate behavior and thoughts. Second, we need a better theory of practices that models implicit coordination of language use, ways of interacting, and ways of thinking. Third, as our pretheoretic framework suggests, the worlds of signs and practices need to be theoretically linked. Then researchers might think about how existing concepts can be reshaped beneficially by using the proposed ontology. What are value "drivers" in service? How do people create (cocreate) common understanding of the signs they use, especially if they communicate in a non-face-to-face manner? Are there ways of better understanding the implicit parts of actions 
and interactions? Is a full understanding of signs' use necessary for valuable interactions? Can value be cocreated without understanding a particular service?

\section{Toward a Research Agenda}

If the above-mentioned research needs are met, it can help to more soundly address a more managerial research agenda, such as the following:

1. How can IT managers map everyday practices to develop ideas for service innovation? How can these ideas be expanded beyond employees, suppliers, and customers to understand practices of stakeholders and how to serve them?

2. How can firms develop narrative descriptions (semantics) of everyday practices that provide the metadata needed to develop service innovations? Can this type of metadata be premarket in nature and perhaps suggestive of how firms can become practice centric (to complement being market centric) or serve as a catalyst for firms to create new markets? All business processes are service(s), and thus there is a need to do the same research of business processes within the firm to develop better business process innovations.

3. What determines the smallest level of components or building blocks for enabling modular service innovations? This can be especially helpful for outsourcing microprocesses both in the firm and in the household.

4. How can firms rebundle business or household processes to provide new services? How can these new services drive market creation?

5. How can firms educate and train all of their personnel to be service centric, and how can this enable software and product engineers to be more successful in their innovation efforts?

6. What are the early indicators of the emergence of new practices, and how quickly do markets develop to support these practices? What role can "big data" provide in this regard (Zeng and Lusch 2013)? Are there data analytics that can be developed that are service innovations?

7. Are there unique or special contracting issues that emerge from service innovations that are built on loosely coupled modular components? Are new or modified institutions needed to enable these service innovations to rapidly diffuse?

\section{Concluding Comments}

Service exchange (Vargo and Lusch 2004, 2008) is the foundation of all economies and societies when the actors of these systems specialize through division of skills and competencies or, as Adam Smith (1904) described, through the division of labor. During Smith's era (the late 1700s), the key to national wealth was the production of surplus tangible goods that could be exported and exchanged for other resources. Although tangible goods are still a source of national wealth for some countries, the trend is toward more and more division of skills and competencies to develop IT-related service innovations that are signs and sign systems grounded in explicit coordination of use of language, coordination of sign operation through thinking, and coordination of behavior or (inter)action. Service innovations will increasingly become the source of wealth of nations. However, sign coordination will not create service or economic wealth unless it is linked to practices and the enhancement of these practices because, without enhanced practice, there is no gain in value. In summary, the world of IT-related service innovation is a world that is grounded in sign coordination, enhanced practices, new practices, and improved value in context. 


\section{References}

Araujo L, Kjellberg H, Spencer R (2008) Market practices and forms: Introduction to the special issue. Marketing Theory 8(1):5-14.

Bateson G (2000) Steps to an Ecology of Mind (University of Chicago Press, Chicago).

Baudrillard J (1975) The Mirror of Production, translated by Poster M (Telos Press, St. Louis). [Orig. pub. 1973.]

Baudrillard J (1994) Simulacra and Simulation, translated by Glaser SF (University of Michigan Press, Ann Arbor). [Orig. pub. 1981.]

Baudrillard J (1998) The Consumer Society: Myths and Structures, translated by Turner C (Sage, Paris). [Orig. pub. 1970.]

Berry LL, Shankar V, Parish JT, Cadwallader S, Dotzel T (2006) Creating new markets through service innovation. MIT Sloan Management Rev. 47(2):56-63.

Boulenger V, Hauk O, Pulvermüller F (2009) Grasping ideas with the motor system: Semantic somatotopy in idiom comprehension. Cerebral Cortex 19(8):1905-1914.

Burford S (2011) Complexity and the practice of Web information architecture. J. Amer. Soc. Inform. Sci. Tech. 62(10):2024-2037

Cainelli G, Evangelista R, Savona M (2006) Innovation and economic performance in services: A firm-level analysis. Cambridge J. Econom. 30(3):435-458.

Cherrier H, Murray JB (2004) The sociology of consumption: The hidden facet of marketing. J. Marketing Management 20(5/6):509-525. Christensen CM (1997) The Innovator's Dilemma: When New Technologies Causes Great Firms to Fail (Harvard Business School Press, Boston).

Constantin JA, Lusch RF (1994) Understanding Resource Management: How to Deploy Your People, Products, and Processes for Maximum Productivity (Planning Forum, Oxford, $\mathrm{OH}$ ).

D’Ausilio A, Pulvermüller F, Salmas P, Bufalari I, Begliomini C, Fadiga L (2009) The motor somatotopy of speech perception. Current Biol. 19(5):381-385.

De Jaegher H, Di Paolo E (2007) Participatory sense-making: An enactive approach to social cognition. Phenomenol. Cognitive Sci. 6(4):485-507.

Derrida J (1976) Of Grammatology, translated by Spivak GC (John Hopkins University Press, Baltimore). [Orig. pub. 1967.]

Derrida J (1977) Signature event context. Glyph 1(1):172-197.

Derrida J (1978) Writing and Difference, translated by Bass A (University of Chicago Press, Chicago).

de Saussure F (1959) Course in General Linguistics (Philosophical Library, New York).

Dorner N, Gassmann O, Gebauer H (2011) Service innovation: Why is it so difficult to accomplish? J. Bus. Strategy 32(3):37-46.

Edvardsson B, Olsson J (1996) Key concepts for new service development. Service Indust. J. 16(2):140-164.

Erickson TD (1990) Working with interface metaphors. Laurel B, ed. The Art of Human-Computer Interface Design (Addison-Wesley, Reading, MA), 65-73.

Espinosa JA, Lerch FJ, Kraut RE (2004) Explicit versus implicit coordination mechanisms and task dependencies: One size does not fit all. Sales E, Fiore SM, eds. Team Cognition: Understanding The Factors That Drive Process and Performance (American Psychological Association, Washington, DC), 107-129.

Feldman MS, Orlikowski WJ (2011) Theorizing practice and practicing theory. Organ. Sci. 22(5):1240-1253.

Fichman RG, Dos Santos BL, Zheng Z (2014) Digital innovation as a fundamental and powerful concept in the information systems curriculum. MIS Quart. 38(2):329-353.

Firat AF, Dholakia N, Venkatesh A (1995) Marketing in a postmodern world. Eur. J. Marketing 29(1):40-56. 
Fitzsimmons JA, Fitzsimmons MJ (2000) New Service Development: Creating Memorable Experiences (Sage, Thousand Oaks, CA).

Gallouj F (2002) Innovation in the Service Economy: The New Wealth of Nations (Edward Elgar, Cheltenham, UK).

Gallouj F, Suvana M (2009) Innovation in services: A review of the debate and a research agenda. J. Evolution. Econom. 19(2):149-172.

Gergen KJ (1991) The Saturated Self: Dilemmas of Identity in Contemporary Life (Basic Books, New York).

Gergen KJ (1994) Realities and Relationships: Soundings in Social Construction (Harvard University Press, Cambridge, MA).

Gergen KJ (1999) An Invitation to Social Construction (Sage, London).

Giddens A (1984) The Constitution of Society (University of California Press, Berkeley).

Giddens A (1991) The Consequences of Modernity (Polity Press, Cambridge, UK).

Grönroos C (2008) Service logic revisited: Who creates value? And who co-creates? Eur. Bus. Rev. 20(4):298314.

Hasenfeld Y, ed. (1992) Human Services as Complex Organizations (Sage, Newbury Park, CA).

Houmb SH, Islam S, Knauss E, Jürjens J, Schneider K (2010) Eliciting security requirements and tracing them to design: An integration of common criteria, heuristics, and UMLsec. Requirements Engrg. 15(1):63-93.

Kallinikos J, Aaltonen A, Marton A (2013) The ambivalent ontology of digital artifacts. MIS Quart. 37(2):357370.

Kjellberg H, Helgesson C-F (2006) Multiple versions of markets: Multiplicity and performativity in market practice. Indust. Marketing Management 35(7):839-855.

Kjellberg H, Helgesson C-F (2007) On the nature of markets and their practices. Marketing Theory 7(2):137162.

Knott A (2012) Sensorimotor Cognition and Natural Language Syntax (MIT Press, Cambridge, MA).

Lakoff G, Johnson M (1980) Metaphors We Live By (University of Chicago Press, Chicago).

Lakoff G, Johnson M (1999) Philosophy in the Flesh (Basic Books, New York).

Löbler H (2010) Signs and practices coordinating service and relationships. J. Bus. Market Management 4(4):217-230.

Löbler H (2011) Position and potential of service-dominant logic—Evaluated in an "ism" frame for further development. Marketing Theory 11(1):51-73.

Loreto V, Baronchelli A, Puglisi A (2010) Mathematical modeling of language games. Nolfi S, Mirolli M, eds. Evolution of Communication and Language in Embodied Agents (Springer-Verlag, Berlin), 263-281.

Luhmann N (1995) Social Systems (Stanford University Press, Stanford, CA).

Luhmann N (2006) System as difference. Organization 13(1):37-57.

Lusch RF, Vargo SL (2014) Service-Dominant Logic: Premises, Perspectives, Possibilities (Cambridge University Press, Cambridge, UK).

Lusch RF, Vargo SL, O'Brien M (2007) Competing through service: Insights from service-dominant logic. $J$. Retailing 83(1):5-18.

Lyotard J-F (1984) The Postmodern Condition: A Report on Knowledge (Minnesota University Press, Minneapolis).

Maturana H, Varela FJ (1987) The Tree of Knowledge: The Biological Roots of Human Understanding (Shambhala Publications, Boston). 
Michel S, Brown SW, Gallan AS (2008) An expanded and strategic view of discontinuous innovations: Deploying a service-dominant logic. J.Acad. Marketing Sci.36(1):54-66.

Mokyr J (2002) The Gifts of Athena: Historical Origins of the Knowledge Economy (Princeton University Press, Princeton, NJ).

Nambisan S, Sawhney M (2007) The Global Brain: Your Roadmap for Innovating Faster and Smarter in a Networked World (Prentice Hall, Upper Saddle River, NJ).

Nathan LP (2012) Sustainable information practice: An ethnographic investigation. J. Amer. Soc. Inform. Sci. Tech. 63(11):2254-2268.

Nijssen EJ, Hillebrand B, Vermeulen PAM, Kemp RGM (2006) Exploring product and service innovation similarities and differences. Internat. J. Res. Marketing 23(3):241-251.

Nolfi S, Mirolli M, eds. (2010) Evolution of Communication and Language in Embodied Agents (SpringerVerlag, Berlin).

Norman DA, Verganti R (2014) Incremental and radical innovation: Design research vs. technology and meaning change. Design Issues 30(1):78-96.

Normann R (2001) Reframing Business: When the Map Changes the Landscape (John Wiley \& Sons, Chichester, UK).

Ordanini A, Parasuraman A (2011) Service innovation viewed through a service-dominant logic lens: A conceptual framework and empirical analysis. J. Service Res. 14(1):3-23.

Orlikowski WJ (1992) The duality of technology: Rethinking the concept of technology in organizations. Organ. Sci. 3(3):398-427.

Orlikowski WJ (2000) Using technology and constituting structures: A practice lens for studying technology in organizations. Organ. Sci. 11(4):404-428.

Paswan A, D'Souza D, Zolfagharian MA (2009) Toward a contextually anchored service innovation typology. Decision Sci. 40(3):513-540.

Polanyi M (1962) Personal Knowledge Towards a Post-Critical Philosophy (University of Chicago Press, Chicago).

Rai A, Sambamurthy V (2006) The growth of interest in services management: Opportunities for information systems scholars. Inform. Systems Res. 17(4):327-331.

Reckwitz A (2002) Toward a theory of social practices: A development in culturalist theorizing. Eur. J. Soc. Theory 5(2):243-263.

Robertson TS (1967) The process of innovation and the diffusion of innovation. J. Marketing 31(1):14-19.

Rosenbaum H, Shachaf P (2010) A structuration approach to online communities of practice: The case of Q\&A communities. J. Amer. Soc. Inform. Sci. Tech. 61(9):1933-1944.

Rust $\mathrm{R}$ (2004) If everything is a service, why is this happening now, and what difference does it make. $J$. Marketing 68(1):23-24.

Sawhney M, Verona G, Prandelli E (2005) Collaborating to create: The Internet as a platform for customer engagement in product innovation. J. Interactive Marketing 19(4):4-17.

Schatzki T (1996) Social Practices: A Wittgensteinian Approach to Human Activity and the Social (Cambridge University Press, Cambridge, UK).

Schatzki T (2007) Introduction. Human Affairs 17(2):97-100.

Schau HJ, Muñiz AM Jr, Arnould EJ (2009) How brand community practices create value. J. Marketing 73(5):30-51.

Sheehan J (2006) Understanding service sector innovation. Comm. ACM 49(7):43-47.

Sheth JN, Sisodia RS, Sharma A (2000) The antecedents and consequences of customer-centric marketing. $J$. Acad. Marketing Sci. 28(1):55-66. 
Smith A (1904) An Inquiry into the Nature and Causes of the Wealth of Nations, edited by Cannan E (Methuen \& Co., London). [Orig. pub. 1776 (W. Strahan and T. Cadell, London).]

Smith DC, Kirby C, Kimball R, Harslem E (1982) The star user interface: An overview. Proc. AFIPS National Comput. Conf. (ACM, New York), 515-528.

Spencer-Brown G (1969) Laws of Form (Allen \& Unwin, London).

Srinivasan R (2007) Ethnomethodological architectures: Information systems driven by cultural and community visions. J. Amer. Soc. Inform. Sci. Tech. 58(5):723-733.

Steels L (2010) Modeling the formation of language: Embodied experiments. Nolfi S, Mirolli M, eds. Evolution of Communication and Language in Embodied Agents (Springer-Verlag, Berlin), 233-261.

Swanson EB (1994) Information systems innovation among organizations. Management Sci. 40(9):1069-1092.

Toups ZO, Kerne A (2007) Implicit coordination in firefighting practice: Design implications for teaching fire emergency responders. Proc. SIGCHI Conf. Human Factors Comput. Systems (ACM, New York), 707-716.

Vargo SL, Lusch RF (2004) Evolving to a new dominant logic for marketing. J. Marketing 68(1):1-17.

Vargo SL, Lusch RF (2008) Service-dominant logic: Continuing the evolution. J. Acad. Marketing Sci. 36(1):110.

Vargo SL, Lusch RF (2011) It's all B2B . . and beyond: Toward a systems perspective of the market. Indust. Marketing Management 40(2):181-187.

Venkatesh A, Penaloza L, Firat AF (2006) The market as a sign system and the logic of the market. Lusch RF, Vargo SL, eds. The Service-Dominant Logic of Marketing, Dialog, Debate and Directions (M.E. Sharpe, New York), 251-265.

von Krogh G, Haefliger S, Spaeth S, Wallin MW (2012) Carrots and rainbows: Motivation and social practice in open source software development. MIS Quart. 36(2):649-676.

Wittgenstein L (1960) The Blue and Brown Books, 2nd ed. (Harper \& Row, New York).

Wittgenstein L (2008) Philosophical Investigations: The German Text, with a Revised English Translation (Blackwell, Oxford, UK).

Yoo Y, Henfridsson O, Lyytinen K (2010) The new organizing logic of digital innovation: An agenda for information systems research. Inform. Systems Res. 21(4):724-735.

Zeng D, Lusch R (2013) Big data analytics: Perspective shifting from transactions to ecosystems. IEEE Intelligent Systems 28(2):2-5. 